\title{
Aerobic biogenesis of selenium nanospheres by Bacillus cereus isolated from coalmine soil
}

\author{
Soniya Dhanjal, Swaranjit Singh Cameotra*
}

\begin{abstract}
Background: Microorganisms that are exposed to pollutants in the environment, such as metals/metalloids, have a remarkable ability to fight the metal stress by various mechanisms. These metal-microbe interactions have already found an important role in biotechnological applications. It is only recently that microorganisms have been explored as potential biofactories for synthesis of metal/metalloid nanoparticles. Biosynthesis of selenium ( $\mathrm{Se}^{\mathrm{O}}$ ) nanospheres in aerobic conditions by a bacterial strain isolated from the coalmine soil is reported in the present study.

Results: The strain CM100B, identified as Bacillus cereus by morphological, biochemical and 16S rRNA gene sequencing [GenBank:GU551935.1] was studied for its ability to generate selenium nanoparticles (SNs) by transformation of toxic selenite $\left(\mathrm{SeO}_{3}{ }^{2-}\right)$ anions into red elemental selenium ( $\left.\mathrm{Se}^{0}\right)$ under aerobic conditions. Also, the ability of the strain to tolerate high levels of toxic selenite ions was studied by challenging the microbe with different concentrations of sodium selenite $(0.5 \mathrm{mM}-10 \mathrm{mM})$. ESEM, AFM and SEM studies revealed the spherical $\mathrm{Se}^{0}$ nanospheres adhering to bacterial biomass as well as present as free particles. The TEM microscopy showed the accumulation of spherical nanostructures as intracellular and extracellular deposits. The deposits were identified as element selenium by EDX analysis. This is also indicated by the red coloration of the culture broth that starts within 2-3 h of exposure to selenite oxyions. Selenium nanoparticles (SNs) were further characterized by UV-Visible spectroscopy, TEM and zeta potential measurement. The size of nanospheres was in the range of 150-200 nm with high negative charge of $-46.86 \mathrm{mV}$.

Conclusions: This bacterial isolate has the potential to be used as a bionanofactory for the synthesis of stable, nearly monodisperse $\mathrm{Se}^{0}$ nanoparticles as well as for detoxification of the toxic selenite anions in the environment. A hypothetical mechanism for the biogenesis of selenium nanoparticles (SNs) involving membrane associated reductase enzyme(s) that reduces selenite $\left(\mathrm{SeO}_{3}{ }^{2-}\right)$ to $\mathrm{Se}^{0}$ through electron shuttle enzymatic metal reduction process has been proposed.
\end{abstract}

\section{Background}

Selenium (Se), belonging to group 16 of the periodic table is well known for its photoelectric and semiconductor properties. It is used in solar cells, rectifiers, photographic exposure meters and xerography [1]. Amorphous selenium nanoparticles (SNs) possess unique photoelectric, semiconducting and X-ray-sensing properties. These nanoparticles also show biological activity and good adsorptive ability due to interaction between the nanoparticles and $\mathrm{NH}, \mathrm{C}=\mathrm{O}, \mathrm{COO}^{-}$and $\mathrm{C}-\mathrm{N}$ groups of proteins [2]. Selenium nanoparticles have also been developed for applications in medical

\footnotetext{
* Correspondence: ssc@imtech.res.in

Institute of Microbial Technology, Sector 39-A, Chandigarh 160036, India
}

diagnostics [3]. Studies on the biological toxicity of selenium and its nanoforms revealed that nano-selenium showed equal efficiency in increasing the activities of glutathione peroxidase and thioredoxin reductase [4]. Gao et al. [5] demonstrated the antioxidant properties of hollow spherical nanoparticles of selenium. Similar observations that nano-Se can serve as an antioxidant with reduced risk of selenium toxicity was reported by Wang et al. [6]. The size of nanoparticles play an important role in their biological activity as $5-200 \mathrm{~nm}$ nano-Se can directly scavenge free radicals in vitro in a sizedependent fashion [7]. Several methods including $\gamma$-irradiation and laser ablation have been applied to synthesize selenium nanoparticles but most widely used 
synthetic approach for preparing selenium nanoparticles is chemical reduction [8].

Recently, there has been increasing interest in synthesis of nanoparticles using biological systems leading to the development of various biomimetic approaches. Microorganisms, such as bacteria, yeast and fungi play an important role in recycling of minerals in the environment. Some of these microorganisms can survive and grow even at high metal ion concentrations. The toxicity of metal ions is reduced or eliminated by changing the redox state of the metal ions and in the process leading to the formation of well-defined nanoscale particles in some cases [9].

Selenium occurs in variety of oxidation states like selenate $\left(\mathrm{SeO}_{4}{ }^{2-}\right) /$ selenite $\left(\mathrm{SeO}_{3}{ }^{2-}\right)$ oxyions, wherein the oxidation states are +6 and +4 ; elemental selenium $\left(\mathrm{Se}^{0}\right)$ and selenide $\left(\mathrm{Se}^{2-}\right)$. The toxicity of these states is related to their degrees of solubility in water and hence their bioavailability. Elemental selenium can exist in forms other than red amorphous selenium $\left(\mathrm{Se}^{0}\right)$ as selenate $\left(\mathrm{SeO}_{4}{ }^{2-}\right) /$ selenite $\left(\mathrm{SeO}_{3}{ }^{2-}\right)$ which are highly water soluble and as selenide $\left(\mathrm{Se}^{2-}\right)$ which is gaseous in nature. Among the various selenium species, selenite $\left(\mathrm{SeO}_{3}{ }^{2-}\right)$ reduction has attracted a great deal of attention as potential compound for microbial reduction due to its high toxicity. Se-reducing bacteria are ubiquitous and occur in diverse terrestrial and aquatic environments [10]. A few microorganisms have been well characterized for their ability to reduce toxic selenate and selenite oxyions into non-toxic elemental form $\mathrm{Se}^{0}$ under aerobic and anaerobic conditions [10-13].

The biogenesis of selenium nanostructures during the dissimilatory respiration was reported by Oremland et al. [14] during the dissimilatory respiration. $\mathrm{Se}^{0}$ particles formed by the Se-respiring bacteria Sulfurospirillum barnesii, Bacillus selenitireducens and Selenihalanaerobacter shriftii are structurally unique compared to elemental selenium formed by chemical synthesis. The three anaerobes used toxic selenium oxyions as the electron acceptors during anaerobic respiration which resulted in the formation of stable, uniform nanospheres of selenium (diameter $\sim 300 \mathrm{~nm}$ ). The majority of studies on the biogenesis of selenium nanoparticles have focused on anaerobic systems. However, anaerobic conditions have limitations, such as culture conditions and isolate characteristics that make optimization and scaleup in bio-manufacturing processes tedious and challenging [15]. Selenium-tolerant aerobic microorganisms may provide an opportunity to overcome these limitations in the biosynthetic processes. Very few studies have reported the aerobic formation of selenium nanoparticles by microorganisms. The generation of selenium nanospheres by soil bacteria Pseudomonas aeruginosa and Bacillus sp. under aerobic conditions has recently been reported $[15,16]$. These studies include the partial characterization of selenium nanospheres formed by the two isolates. The aim of the present investigation was to study the possible formation of selenium $\left(\mathrm{Se}^{0}\right)$ nanospheres in aerobic conditions by a Se-reducing bacterial strain (CM100B) isolated from a coalmine soil of West Bengal, India.

\section{Methods}

\section{Microorganism and Growth Conditions}

The strain CM100B was isolated from coalmine soil (coal mines located in Asansol, Latitude: $23^{\circ} 41^{\prime} \mathrm{N}$ and Longitude: $86^{\circ} 59^{\prime} \mathrm{E}$, West Bengal, India) by enrichment of the soil sample for one week with sodium selenite $(0.5 \mathrm{mM})$ followed by standard method of dilution plating on tryptic soy agar (TSA) medium supplemented with $0.5 \mathrm{mM}$ sodium selenite. The pure isolate was routinely cultured on TSA plates containing $2 \mathrm{mM}$ selenite at $37^{\circ} \mathrm{C}$.

\section{Morphological, Biochemical and Physiological characterization of the isolate $\mathrm{CM} 100 \mathrm{~B}$}

Biochemical characterization of the strain CM100B was performed following standard methods as described in Bergy's Manual of Systemic Bacteriology, Vol. 1, and Manual for the Identification of Medical Bacteria by Cowan \& Steel (Second edition, Cambridge University press).

\section{6s rRNA gene sequencing and phylogenetic analysis}

For the 16S rRNA gene analysis the genomic DNA was extracted by the CTAB method followed by PCR amplification with universal primers 27F and 1492R. Sequencing of the amplified product was done by dideoxy chain terminator method using the Big Dye terminator kit followed by capillary electrophoresis on an ABI 310 genetic analyzer (Applied Biosystems, USA). The sequence obtained was BLAST searched and compared with sequences of other closely related species retrieved from the GenBank database http://www.ncbi.nlm.nih. gov/BLAST/ followed by alignment using the MEGA software version 4 [17]. A phylogenetic tree was constructed using the neighbor-joining algorithm. Bootstrap analysis was performed to assess the confidence limits of the branching.

\section{Bacterial growth under selenite stress}

The effect of selenite on the growth of the bacterial isolate was determined in the presence of $0.5 \mathrm{mM}, 1 \mathrm{mM}$, $2 \mathrm{mM}, 5 \mathrm{mM}$ and $10 \mathrm{mM}$ of sodium selenite. Sodium selenite was prepared as $1 \mathrm{M}$ stock solution and sterilized by filtration. $250 \mathrm{ml}$ Erlenmeyer flasks containing $100 \mathrm{ml}$ of Tryptic Soya Broth (TSB) supplemented with respective concentrations of selenite were inoculated 
with overnight grown bacterial culture and incubated at $37^{\circ} \mathrm{C}$ at $200 \mathrm{rpm}$. Bacterial growth was measured by the quantification of total protein content of microbial biomass. Protein concentration in bacterial cell extracts was determined by using the Bicinchoninic acid (BCA) method with Bovine Serum Albumin (BSA) as standard. A $1 \mathrm{ml}$ aliquot of bacterial culture was collected at different time intervals of bacterial growth and was centrifuged at $4722 \times g$ (Sigma 1-14) for $10 \mathrm{~min}$. The pellet was resuspended in $100 \mu \mathrm{l}$ of extraction buffer $(50 \mathrm{mM}$ $\mathrm{Na}_{2} \mathrm{HPO}_{4}, \mathrm{pH} 7 ; 10 \mathrm{mM} \beta$-mercaptoethanol; $10 \mathrm{mM}$ $\mathrm{Na}_{2}$ - EDTA; 0.1\% Sodium dodecyl sulphate (SDS); $0.1 \%$ Triton X-100). The resulting suspension was sonicated for $5 \mathrm{~min}$ and centrifuged at $10625 \times g$ for $15 \mathrm{~min}$ at $4^{\circ} \mathrm{C}$. The supernatant was collected and measured for protein content. Flask with inoculum without the addition of selenite served as control.

\section{Reduction of selenite by strain CM100B}

To determine the reduction of selenite by the bacterial isolate, the organism was exposed to $2 \mathrm{mM}$ selenite. Samples were collected at $2 \mathrm{~h}$ intervals and centrifuged at $1844 \times g$ to separate the bacterial biomass and the supernatant. Se content in the supernatants was determined by Atomic absorption spectrophotometer (AA6800, Shimadzu) in Hydride Vapor Generation mode, with a selenium cathode lamp. An air-acetylene (oxidizing) flame was used and a wavelength of $196 \mathrm{~nm}$ was chosen for the purpose of absorption of incident light.

\section{Flow Cytometry}

The relative decrease in the size of the cell population under selenite stress was determined by Forward Scatter using FACS Calibur (Becton-Dickinson). The strain CM100B was grown in the presence of $5 \mathrm{mM}$ sodium selenite. An aliquot of $1 \mathrm{ml}$ bacterial culture was collected at regular time intervals of bacterial growth to determine the cell size. The samples were centrifuged at $1180 \times g$ for $10 \mathrm{~min}$. The cell pellet was gently washed twice with phosphate buffered saline (PBS) pH 7.2 and re-suspended in it for analysis. Culture without addition of selenite oxyions served as control.

\section{Microscopic studies}

\section{Environmental Scanning Electron Microscopy (ESEM)}

ESEM examination of the culture was done by growing the cells in the presence of $2 \mathrm{mM}$ selenite for $24 \mathrm{~h}$. The sample was applied directly on the stub and scanned with a Hitachi Scanning Electron Microscope under variable pressure in ESEM mode.

\section{Scanning Electron Microscopy}

Strain CM100B was grown in TSB supplemented with 2 $\mathrm{mM}$ sodium selenite at $37^{\circ} \mathrm{C}$. After $24 \mathrm{~h}$ of incubation, cells were centrifuged at $1844 \times g$ at $4^{\circ} \mathrm{C}$ for $10 \mathrm{~min}$ and scanning electron microscopic studies were performed on the processed samples. Sample processing involves washing, fixing and drying of cells. Harvested cells were washed thrice with phosphate buffer saline (PBS, $\mathrm{pH}$ 7.4) and layered onto polylysine coated cover slips. Fixation was done with modified Karnovsky's fixative (2\% paraformaldehyde and $2.5 \%$ glutaraldehyde in $0.1 \mathrm{M}$ sodium phosphate buffer, $\mathrm{pH}$ 7.4). Cells were again washed with PBS and distilled water. Fixed cells were dehydrated through a series of alcohol dehydration steps (30\%, 50\%, 70\%, 90\% and 100\%) and finally layered with t-butyl alcohol for freeze drying and sputter coated. The samples were then viewed under Scanning Electron Microscope (Carl Zeiss NTS, GmbH, Germany).

\section{Atomic Force Microscopy}

The samples were centrifuged at $4722 \times g$ for $10 \mathrm{~min}$. The acquired cell pellet was gently washed twice with deionized-distilled water and re-suspended in it. $5 \mu \mathrm{l}$ cell suspension was put on the freshly cleaved mica surface and then immediately dried with nitrogen gas. All AFM experiments were carried out by NTMDT Solver pro 7 Atomic Force Microscope using a Si tip. AFM imaging was done in tapping mode.

\section{Transmission Electron Microscopy (TEM)}

For ultrastructural studies, $24 \mathrm{~h}$ old culture grown in the presence of $2 \mathrm{mM}$ sodium selenite was centrifuged at $1844 \times g$ for $15 \mathrm{~min}$, washed thrice with $10 \mathrm{mM}$ phosphate buffer, pH 7.4 and fixed for $10-12 \mathrm{~h}$ at $4^{\circ} \mathrm{C}$ in modified karnovsky's fixative. After successive washings in $10 \mathrm{mM}$ sodium phosphate buffer $\mathrm{pH} 7.4$ cells were post fixed in $1 \%$ osmium tetroxide in the same buffer. After several washes in the same buffer, cells were dehydrated in graded acetone solutions (30\%, 50\%, 70\%, 90\% and $100 \%$ for 15 min each) and embedded in CY 212 araldite $(10 \mathrm{ml})$, along with Dodecenyl Succinic Anhydride (DDSA) as hardner $(10 \mathrm{ml})$, and tri(dimethylaminomethyl) phenol (DMP-30) as catalyst $(0.4 \mathrm{ml})$. Ultrathin sections of 60-80 nm thickness were cut using an ultracut E (Reichert Jung) ultra-microtome and the sections stained with alcoholic uranyl acetate (saturated solution in ethanol) for 2 min and subsequently in lead citrate for 2 min before examining the grids in HRTEM Technai G20-stwin $(200 \mathrm{kV})$ Transmission Electron Microscope. Cells grown for the same time period without the addition of the selenite were taken as control and processed similarly.

\section{Elemental composition analysis with energy dispersive X-ray} (EDX)

To ascertain the reduction of $\mathrm{Se}^{4+}$ to elemental selenium $\left(\mathrm{Se}^{0}\right)$ the samples were processed by a method similar to that used for TEM studies. The selected areas within TEM sections were subjected to elemental composition analysis using an EDX (Bruker AXS Inc. USA, Quantax-200) micro-analysis system coupled to a 
Transmission Electron Microscope. Sample collected from the culture without addition of selenite $\left(\mathrm{SeO}_{3}{ }^{2-}\right)$ was taken as control.

\section{Recovery of selenium nanoparticles from the culture broth}

Bacterial strain inoculated in $300 \mathrm{ml}$ TSB amended with

$2 \mathrm{mM}$ sodium selenite and incubated at $37^{\circ} \mathrm{C}$ at 200 $\mathrm{rpm}$ for $48 \mathrm{~h}$. The culture broth was centrifuged at $10020 \times g$ (Hermle centrifuge, $\mathrm{Z36HK})$ at $4^{\circ} \mathrm{C}$ for $10 \mathrm{~min}$. The pellet was discarded and the cell-free medium was centrifuged at $41410 \times g$ at $4^{\circ} \mathrm{C}$ for $30 \mathrm{~min}$. The supernatant was discarded and the pellet with the selenium-containing particles was re-suspended in water. The suspension was washed twice by repeating the two centrifugation steps.

\section{Characterization of reduced selenite}

The absorption spectra of the red elemental selenium particles suspended in aqueous solution was recorded using a Hitachi U2800 spectrophotometer by wavelength scan from 300-1100 nm setting the baseline with water. TEM studies were carried out using JEM 2100 (JEOL) microscope operating at $120 \mathrm{kV}$ accelerating voltage. Samples were prepared by placing a drop of selenium particles suspended in water on carbon-coated TEM grids. The film on the TEM grids was allowed to dry for $5 \mathrm{~min}$ at room temperature before analysis. Charge distribution (zeta potential) was analyzed using dynamic light scattering system (Beckman Coulter, USA) by illuminating the solution of selenium particles with $\mathrm{He}-\mathrm{Ne}$ Laser $(633 \mathrm{~nm})$ in a sample cell.

\section{Determining the membrane-associated reductase activity}

The culture was grown to log phase and centrifuged at $3910 \times g$ (Hermle centrifuge, $\mathrm{Z} 36 \mathrm{HK})$ for $10 \mathrm{~min}$ at $4^{\circ} \mathrm{C}$ to obtain the cell pellet. Pellet was washed with $10 \mathrm{mM}$ Tris- $\mathrm{Cl}(\mathrm{pH}$ 7.5) twice and re-suspended in the same buffer for sonication. After sonication, the cell lysate was centrifuged at $22540 \times g$ for $40 \mathrm{~min}$ to separate the soluble and membrane fractions. The total protein content was estimated by Bradford method using BSA as standard. Selenite reductase activity was determined using the following reaction mixture: $5 \mathrm{ml} \mathrm{TSB}, 100 \mu \mathrm{g}$ of protein, $5 \mathrm{mM}$ sodium selenite. The reaction mixture was incubated at $37^{\circ} \mathrm{C}$ for 3-4 h. Reaction mixture without addition of membrane or soluble fractions served as controls.

\section{Results and Discussion}

Characterization of selenite tolerant bacterium isolated from coalmine soil

Selenium is a very coalphile element, having strong affinity to organic and inorganic matter present in coals. The average selenium content in hard coals and brown coals is estimated to be $1.6 \pm 0.1$ and $1.0 \pm 0.15 \mathrm{ppm}$, respectively [18]. Therefore, there was high probability of finding an efficient selenium transforming microbe from the collected coalmine soil. The enrichment of coalmine soil with selenite oxyions for over a period of 7 days resulted in isolation of selenite tolerant bacterial strain CM100B. The bacterial isolate was subjected to characterization by morphological, biochemical and molecular methods. It is a Gram-positive, facultative anaerobic, spore-forming, rod shaped, flagellated bacterium. Temperature for growth ranged from $15^{\circ} \mathrm{C}-42^{\circ} \mathrm{C}$ (optimum $37^{\circ} \mathrm{C}$ ), pH values 5-11 (optimum $\mathrm{pH} 7.5$ ), salt concentration $(\mathrm{NaCl} \%)$ up to $7.5 \%$. Biochemical analysis shows that it is positive for catalase, oxidase, hydrolysis of gelatin, starch, casein and negative for citrate, methyl red, Voges-Proskauer, nitrate, urea hydrolysis and oxidation/fermentation tests. Acid is produced from carbohydrates namely dextrose, fructose, maltose, mannose, sucrose and trehalose. The results of 16S rRNA (1439 bp) gene sequence analysis of the strain suggested that it belongs to the genus Bacillus sp. [GenBank: GU551935.1]. In the phylogenetic tree the strain CM100B formed a coherent branch with Bacillus cereus (Fig. 1)The isolate CM100B also showed high sequence similarity of $99 \%$ to Bacillus cereus. Therefore, on the basis of the above results the strain CM100B was characterized as Bacillus cereus.

\section{Growth on selenite $\left(\mathrm{SeO}_{3}{ }^{2-}\right)$ oxyion and evaluation of selenite $\left(\mathrm{SeO}_{3}{ }^{2-}\right)$ reducing ability}

In order to determine the toxicity of selenite $\left(\mathrm{SeO}_{3}{ }^{2-}\right)$ to the microorganism, the growth profile of the bacteria was studied by addition of different concentrations of sodium selenite $(0.5 \mathrm{mM}, 1 \mathrm{mM}, 2 \mathrm{mM}, 5 \mathrm{mM}$ and $10 \mathrm{mM})$ in the growth medium under aerobic conditions. The strain CM100B formed reddish cell suspension which indicated its ability to reduce the toxic, colorless, soluble selenite $\left(\mathrm{SeO}_{3}{ }^{2-}\right)$ ions to nontoxic, red elemental insoluble form of selenium $\left(\mathrm{Se}^{0}\right)$. It is worth noting that the formation of red precipitate of elemental selenium started after $2 \mathrm{~h}$ of exposure to selenite oxyions which made it difficult to study the growth profile of the strain under selenite stress by spectroscopy due to optical interference from $\mathrm{Se}^{0}$ particles in spectrophotometric measurements. Therefore, the total protein content was estimated at regular time intervals and correlated with the increase in the growth of the microorganism. The growth profile of the strain in the presence of selenite $(0.5 \mathrm{mM}-10 \mathrm{mM})$ was comparable to that of control without addition of selenite (Fig. 2A, Graphically growth is shown in the presence of $5 \mathrm{mM}$ and 10 $\mathrm{mM}$ selenite for clarity, however growth studies were done in the presence of selenite concentrations ranging from $0.5-10 \mathrm{mM}$ as mentioned above). Simultaneous protein estimation by BCA method indicated that very short lag period occurred during the growth of the microbe either in the presence or absence of selenite. Apparently, selenite was observed to be non-toxic to the strain at the above 


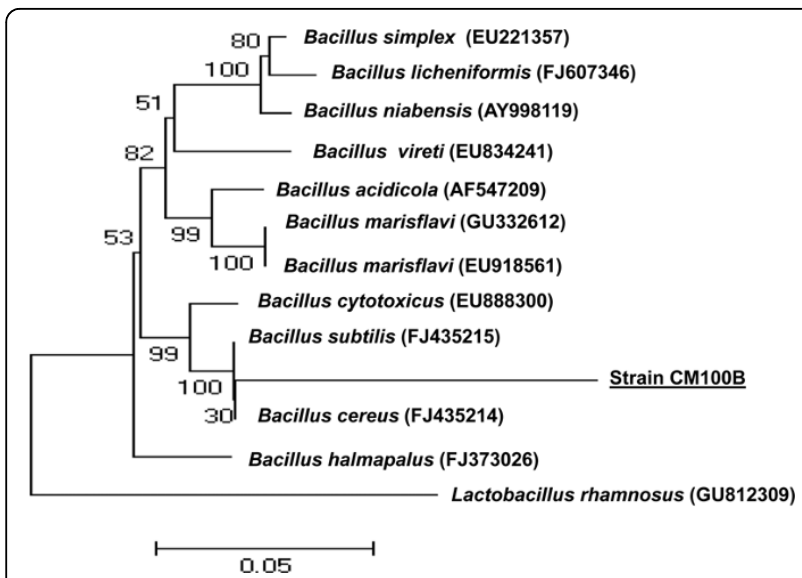

Figure 1 The Neighbor-Joining (NJ) tree, inferred using MEGA software version 4 (Tamura et al. 2007). Bootstrap values expressed as percentage of 1000 replications are given at the nodes. Bar equals $0.05 \%$ sequence variation.

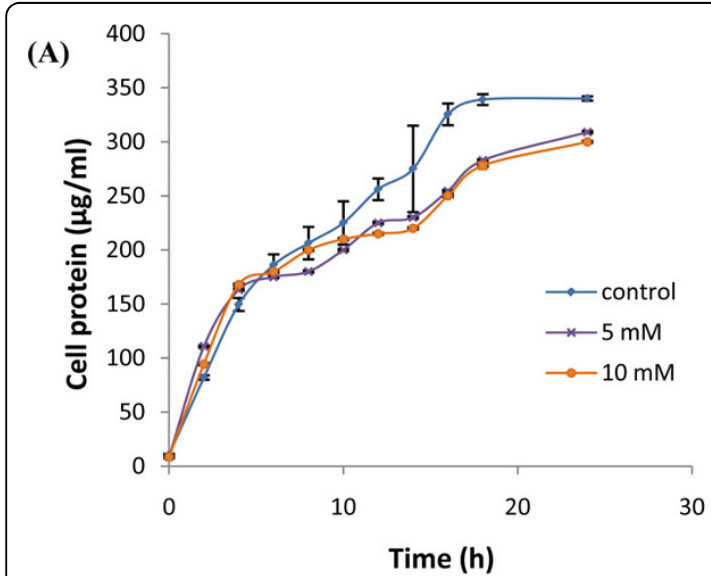

(B)

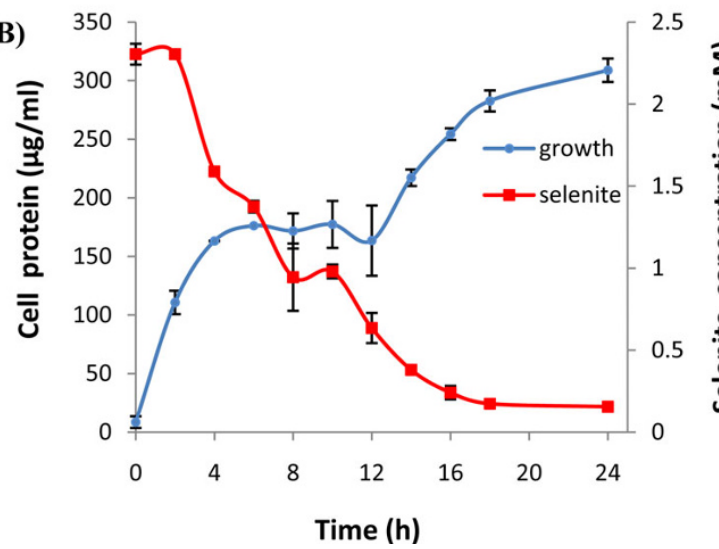

Figure 2 Growth of strain $\mathrm{CM} 100 \mathrm{~B}$ under selenite stress and selenite reduction. (A) Growth profile of strain $\mathrm{CM} 100 \mathrm{~B}$ in the presence of high concentrations of sodium selenite. (B) Time course of microbial growth and selenite $\left(\mathrm{SeO}_{3}{ }^{2-}\right)$ reduction by the strain CM100B. mentioned concentrations. As evident from the Fig. 2B, there was rapid decrease of selenite oxyions in the culture broth within a period of $24 \mathrm{~h}$. Viable cultures challenged with toxic selenite oxyions begin to turn red within $2-3 \mathrm{~h}$ of bacterial growth. A marginal decrease in selenite $\left(\mathrm{SeO}_{3}{ }^{2-}\right)$ concentrations as a result of abiotic reduction by the TSB media was also observed in the uninoculated flasks (data not shown). There was a gradual decrease in average bacterial cell size which was grown in the presence of selenite oxyions as compared to the control cells which were grown without the addition of selenite oxyions. After $12 \mathrm{~h}$ and $24 \mathrm{~h}$ of bacterial growth, the size of the test and the control population was equivalent (Fig. 3A and 3B). A gradual decrease in cell size was observed after $36 \mathrm{~h}$ of cell growth in the presence of selenite oxyions (Fig. 3C). At 48 $\mathrm{h}$ of bacterial growth the test cell population under selenite stress was comparatively smaller in size than the control cells which were grown without the addition of selenite as determined by Forward Scatter in flow cytometric analysis (Fig. 3D)Under the stressful condition of toxic selenite ions the morphology of the cells is altered resulting in decrease in cell size. Possibly, the changes in cell morphology could be explained by the surface/volume ratio. The organisms reduce their cell size and increase their relative surface area for better uptake of the nutrients
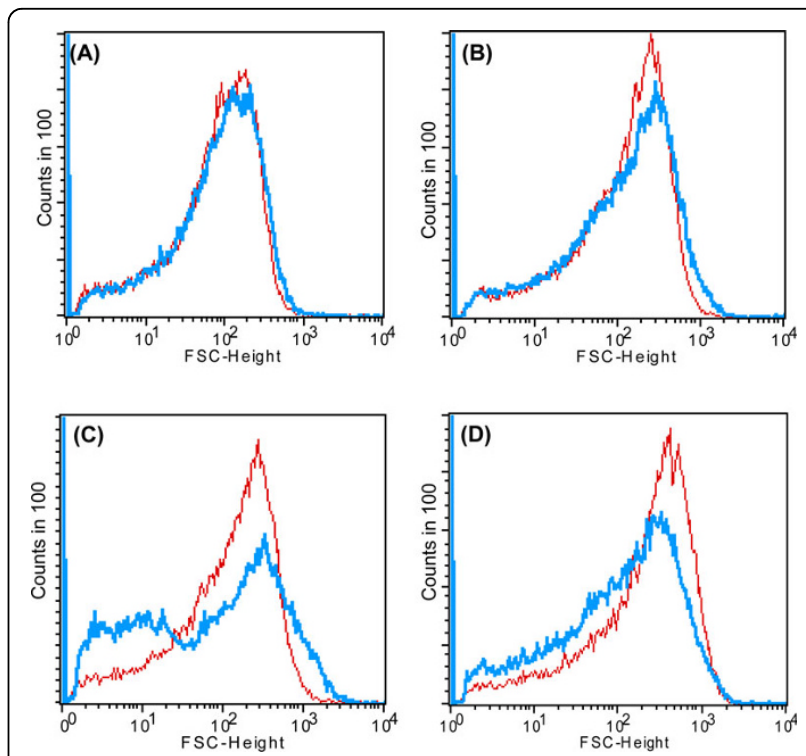

Figure 3 Gradual decrease in average bacterial cell size which was grown in the presence of selenite oxyions as measured by flow cytometry. $X$ axis is $\log$ scale and $Y$ axis indicates the number of bacterial cells (counts in 100). Shift towards left/right on the $X$ axis indicates decrease/increase in cell size in Forward Scattering analysis. Test population (blue) and control population (red). (A) After $12 \mathrm{~h}$ of bacterial growth. (B) After $24 \mathrm{~h}$ of bacterial growth. (C) After $36 \mathrm{~h}$ of bacterial growth and (D) After $48 \mathrm{~h}$, the test population shifts towards left indicating the decrease in cell size of test population which was exposed to selenite stress. 
for survival under environmental stress conditions. The purpose of the growth profile studies was to understand the response of the test organism to high concentrations of selenite which are several orders of magnitude higher than usual levels present in the environment [19].

The above results indicate that reduction of selenite $\left(\mathrm{SeO}_{3}{ }^{2-}\right)$ by the microbe occurred more rapidly than was observed in earlier reports [11,16]. Dungan et al. [19] reported formation of $\mathrm{Se}^{0}$ after $28 \mathrm{~h}$ during studies with Stenotrophomonas maltophilia in the presence of selenite. Therefore, the capability of strain CM100B to rapidly reduce soluble and toxic selenite $\left(\mathrm{SeO}_{3}{ }^{2-}\right)$ to insoluble and unavailable $\mathrm{Se}^{0}$ highlights it as a promising exploitable option for the setup of low-cost biological treatment unit for bioremediating selenium laden effluents. Although the red precipitate indicates the formation of elemental selenium $\left(\mathrm{Se}^{0}\right)$, this fact does not exclude the possibility that there may be additional products, such as selenoamino acids and/or methylated selenides (gaseous products) formed during the selenite transformation process.

\section{Localization of reduced selenite $\left(\mathrm{SeO}_{3}{ }^{2-}\right)$ in the bacterial cells}

Environmental Scanning Electron Microscopic (ESEM) study of bacterial culture obtained from the selenite-supplemented medium inoculated with strain CM100B revealed spherical structures associated with the cellular biomass (Fig. 4A and 4B). In Atomic Force Microscopic (AFM) imaging nanospheres of diameter ranging from 150-200 nm were observed in the extracellular medium (Fig. 5). Scanning electron microscopy (SEM) also showed spherical nanospheres of size ranging from 150-200 nm scattered around the cells as free deposits and also present as aggregates attached to bacterial cell mass (Fig. $6 \mathrm{~A}, \mathrm{~B}, \mathrm{C}$ and 6D). Thus, the unique nature of this isolate is the potential to reduce the toxic selenite ions aerobically with concomitant generation of selenium nanospheres in the culture medium.

Transmission Electron Microscopy (TEM) of the cultures grown in the presence of selenite further

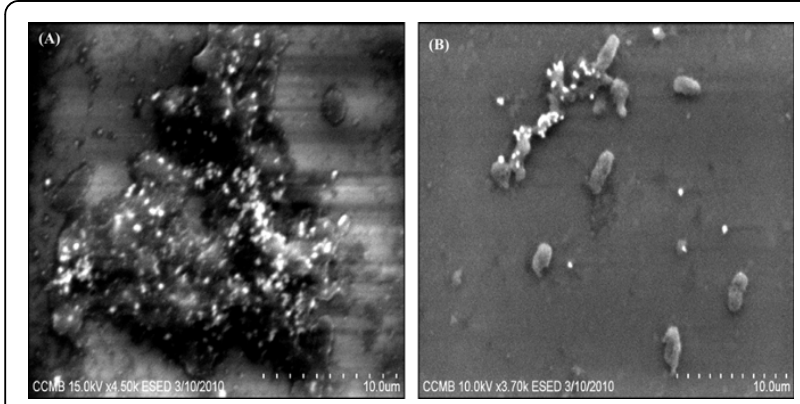

Figure 4 (A) and (B) Environmental Scanning Electron Micrographs show the adherence of Selenium nanospheres to bacterial cell surface.

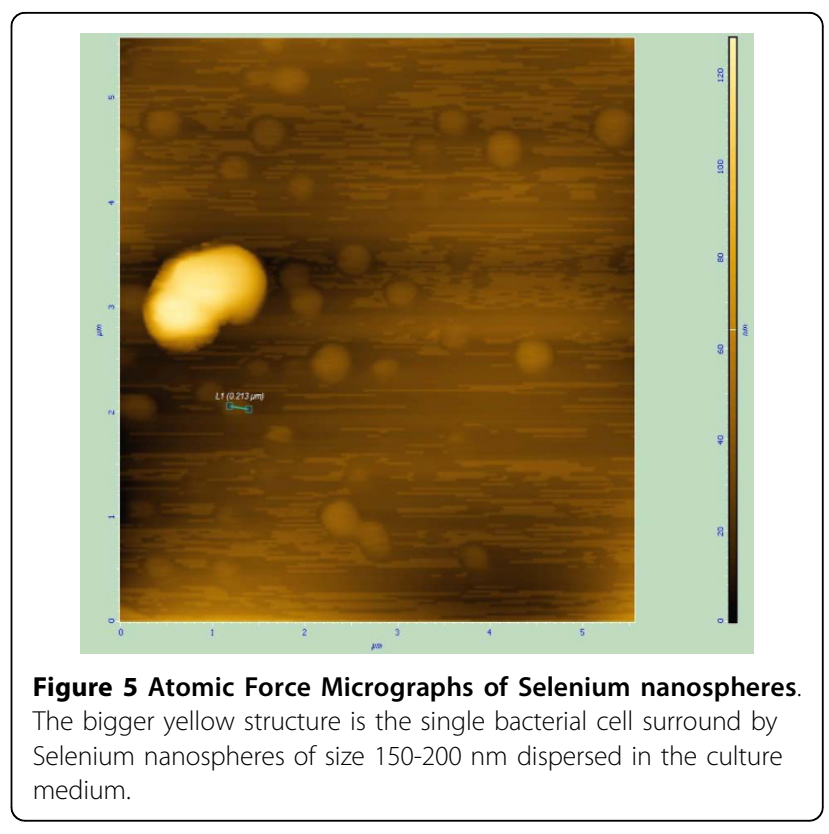

confirmed the spherical intracellular and extracellular deposits of selenium nanospheres. (Fig. 7A).Studies have shown that active efflux of the metal is a frequently utilized strategy to produce tolerance by lowering the intracellular concentration to subtoxic levels [20]. However, our data showing intracellular nanometer-sized particles of elemental selenium $\left(\mathrm{Se}^{0}\right)$ suggest that efflux pumps probably do not mediate the metalloid tolerance mechanism in strain CM100B since selenite tolerance is associated to an intracellular reduction of these oxyanions and then by their accumulation inside the cytoplasm or periplasmic space of the bacterial cell and subsequent exudation by the bacterial cell. The chemical microanalysis (TEM-EDX) of reddish colonies of strain $\mathrm{CM} 100 \mathrm{~B}$ grown in the presence of selenite revealed cytoplasmic and surface attached electron-dense $\mathrm{Se}^{0}$ granules. In EDX analysis, the electron dense $\mathrm{Se}^{0}$ particles produced specific selenium absorption peaks at $1.37 \mathrm{keV}$ (peak SeL $\alpha$ ), 11.22 $\mathrm{keV}$ (peak SeK $\alpha$ ) and $12.49 \mathrm{keV}$ (peak SeK $\beta$ ) Fig. 7B. The uptake and transformations of selenite can be correlated to precipitation of selenium intra and extra-cellularly as observed by Lortie et al. (1992) [11]. The results are significantly similar to the observations by Kessi et al. [21] and Roux et al. [22], which indicated intense Electron Dispersion Spectroscopy (EDS) spectral peaks for $\mathrm{SeK} \alpha$ at $11.22 \mathrm{KeV}$.

\section{Characterization of selenium nanoparticles (SNs) produced by strain $\mathrm{CM} 100 \mathrm{~B}$}

Elemental selenium $\left(\mathrm{Se}^{0}\right)$ in the recent past has been envisaged to have immense medical (free radical scavenging, anti-cancer and anti-oxidative drug applications in 

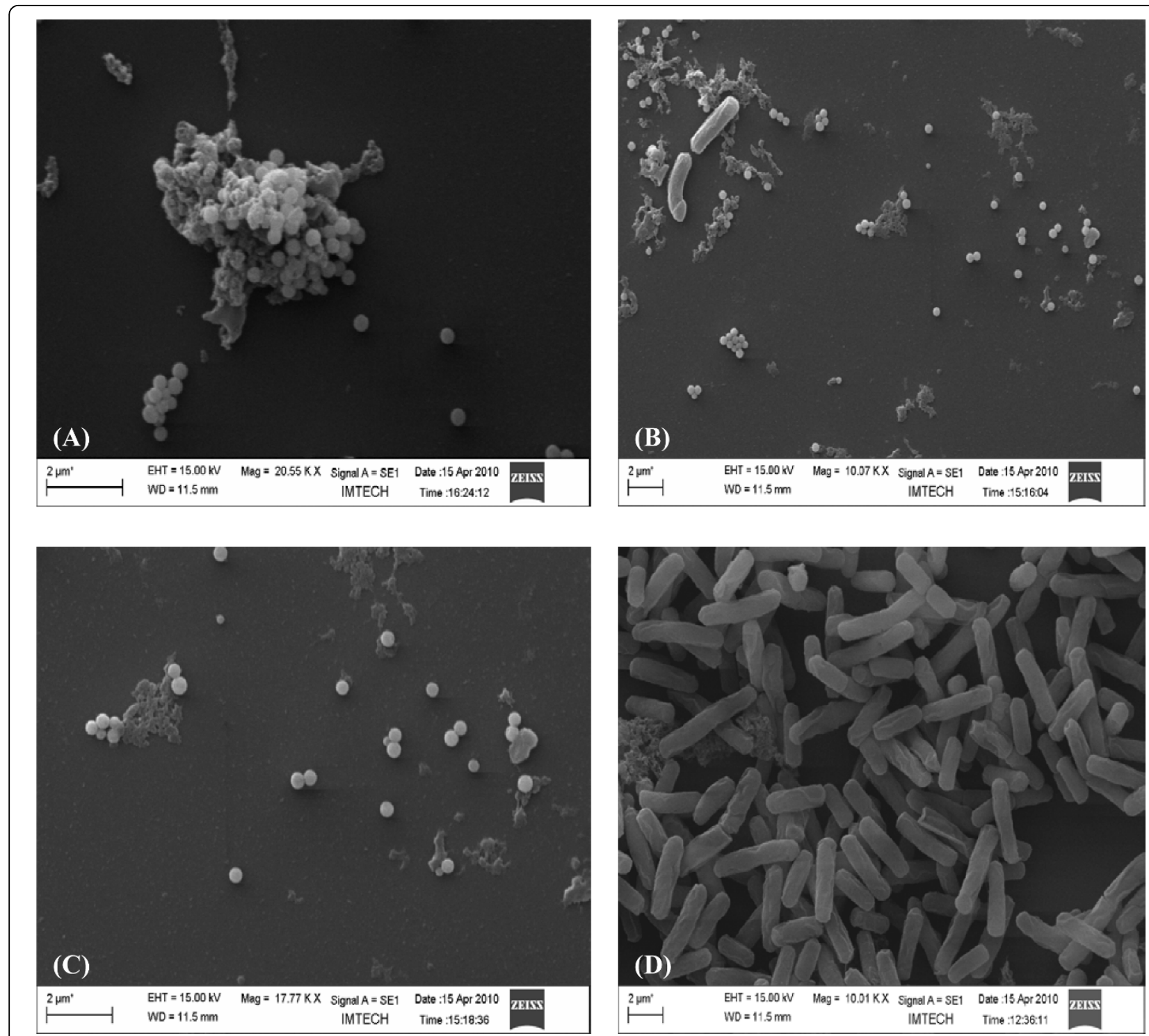

Figure 6 Scanning Electron Micrographs of strain CM100B grown in the presence of $5 \mathrm{mM}$ selenite. (A) Selenium nanospheres adhering to the bacterial cells. (B) Bacterial cells surrounded by selenium nanospheres. (C) Free selenium nanospheres. (D) Control cells grown in TSB without addition of selenite.

medicine) and industrial (glass and optical lens coatings) applications. The growing importance of nano-selenium in diverse variety of applications has lured the researchers to study the biosynthesis of selenium nanoparticles. Therefore, further characterization of the selenium nanospheres produced by the strain CM100B was carried out. The UV-Visible absorption spectra of selenium nanospheres recovered from the culture broth gave characteristic peak at $590 \mathrm{~nm}$ which corresponds to particle size of $182.8 \pm 33.2 \mathrm{~nm}$ [23] (Fig. 8). The size of SNs was further confirmed by TEM imaging which demonstrate that $\mathrm{Se}^{0}$ particles possess an average diameter of 150-200 nm as depicted in Fig. 9A The zeta potential measurements indicate high negative charge $(-46.86 \mathrm{mV})$ on the selenium nanoparticles (Fig. 9B)If all the particles in suspension have a large negative or positive zeta potential then they will tend to repel each other and there is little tendency for the particles to come together. However, if the particles have low zeta potential values then there is propensity of the particles to come together and form aggregates. The high negative charge on $\mathrm{Se}^{0}$ particles is probably resulting in the high stability of the selenium nanospheres without forming aggregates and these particles do not transform to black amorphous form when kept for prolonged period of time of more than a month. The greater stability of 

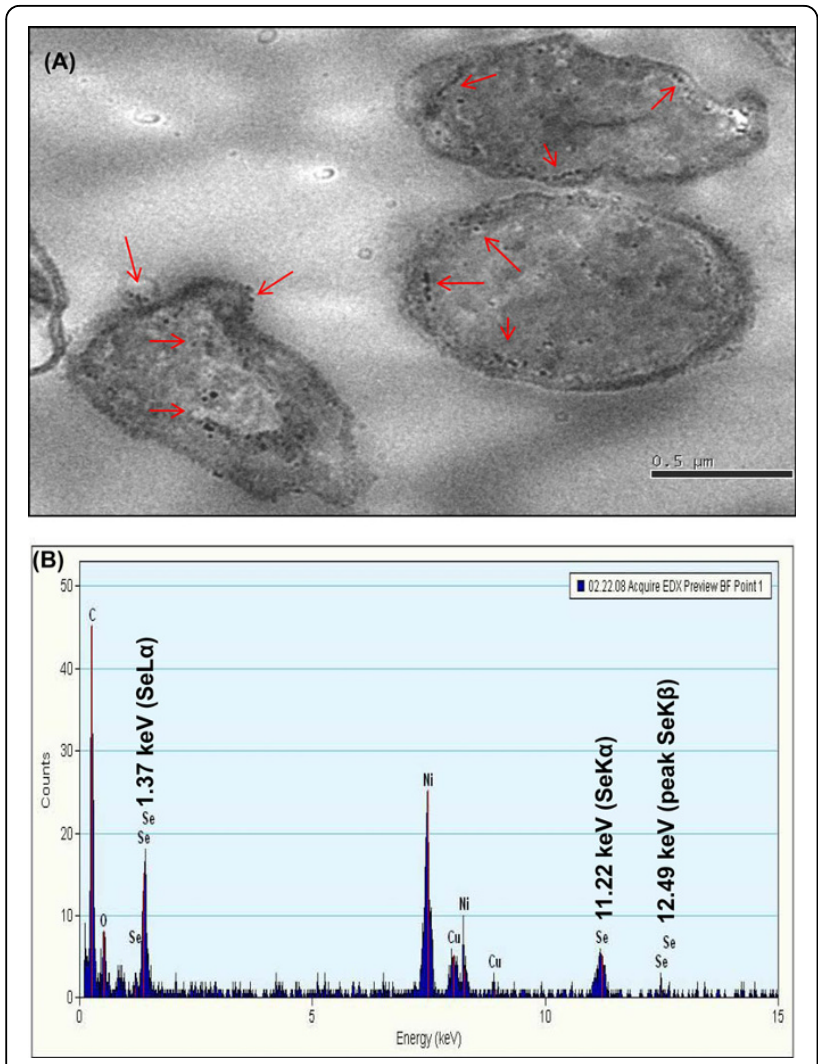

Figure 7 TEM images of localization of selenium nanospheres (indicated by arrows). (A) Intracellular and surface localization of selenium nanospheres in strain $\mathrm{CM} 100 \mathrm{~B}$ under aerobic condition. (B) EDX spectrum of electron dense particles in the bacterial cells indicating the presence of selenium.

allotropic form of $\mathrm{Se}^{0}$ produced by bacteria or precipitated into cell-free medium obtained from the stationary phase culture implies that $\mathrm{Se}^{0}$ is tightly bound to some substances produced by cells and is protected from further transformation to black form [21].

Pioneering study in characterizing the nano-hollow $\mathrm{Se}^{0}$ spheres was carried out by Oremland et al. [14] who proposed that nanospheres are composed of interconnected three-dimensional nets of selenium in which both the chain and ring structural aspects are maintained, factors that resulted in the spherical shape of the nanospheres. Furthermore, the $\mathrm{Se}^{0}$ particles precipitated by the three anaerobic bacteria (Sulfurospirillum barnesii, Bacillus selenitireducens and Selenihalanaerobacter shriftii) exhibited large variations in UV-visible and Raman spectral features, suggesting different species of Se-reducing bacteria produce $\mathrm{Se}^{0}$ biominerals with different atomic structures. These structural variations were attributed to the diversity of enzymes that catalyze the reduction of selenium oxyanions. However, in another study under aerobic conditions, Bacillus sp. was reported to produce nano-structures showing hexagonal

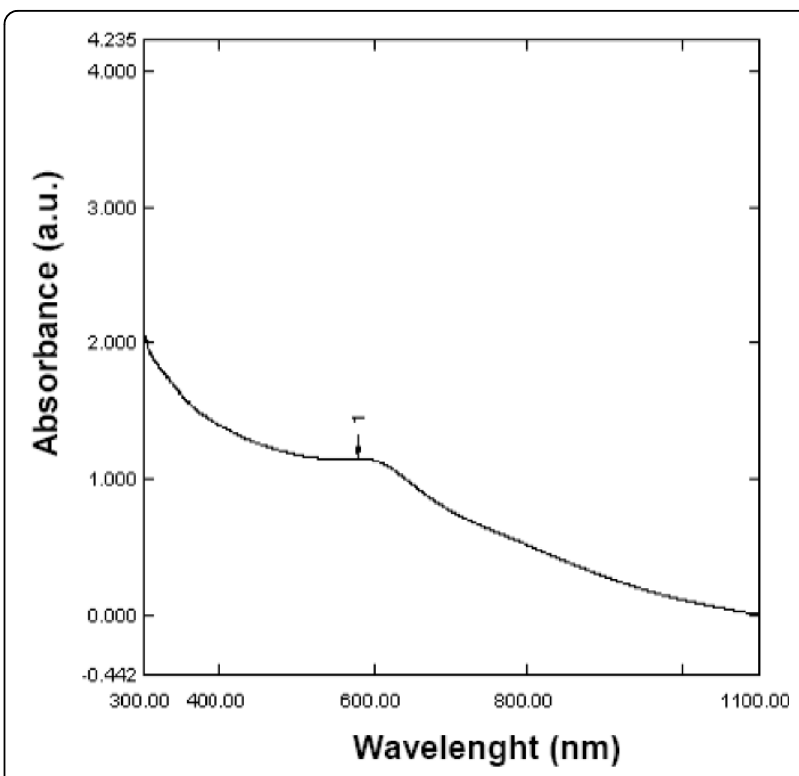

Figure 8 Absorption spectra of selenium nanospheres isolated from Bacillus cereus strain CM100B

facet development and platy nanostructures. Se nanorods were also observed forming rosettes from Se nanospheres associated with the bacterial biomass [15]. Selenium biotransformation in the culture medium by Enterobacter cloacae cells resulted in formation of elemental $\mathrm{Se}^{0}$ of size $<0.1 \mu \mathrm{m}$ in diameter either free in the solution or protruding from the outer surface of the cells [24]. Kessi et al. [21] suggested that the presence of selenium particles on surface and in solution is an indication of vesicular mechanism to expel the bio-transformed selenium. Switzer-Blum et al. [25] examined the formation of small spheres of $\mathrm{Se}^{0}$ on the cell surface of a gram-positive rod, Bacillus selenireducens strain MLS10, after respiratory growth on selenite. Reports of such formations are noted from Stenotrophomonas maltophilia [19], Enterobacter cloacae [24] and Wollinella succinogenes [26].

\section{Proposed mechanism of selenite $\left(\mathrm{SeO}_{3}{ }^{2-}\right)$ detoxification and formation of selenium $\left(\mathrm{Se}^{0}\right)$ nanospheres}

The detoxification mechanism of selenite $\left(\mathrm{SeO}_{3}{ }^{2-}\right)$ reduction in aerobic condition by microorganisms is not yet fully elucidated. More information is however available on the dissimilatory reduction pathways of selenite/selenate in anoxic environments. Microbial transformations of selenium oxyions (selenite/selenate) to insoluble forms such as elemental $\mathrm{Se}^{0}$ may not be the only end product in transformation process as assimilation of organic forms such as selenoamino acids and reduction and methylation of selenium oxyions which yields volatile products, primarily dimethyl selenide has also been observed in some 


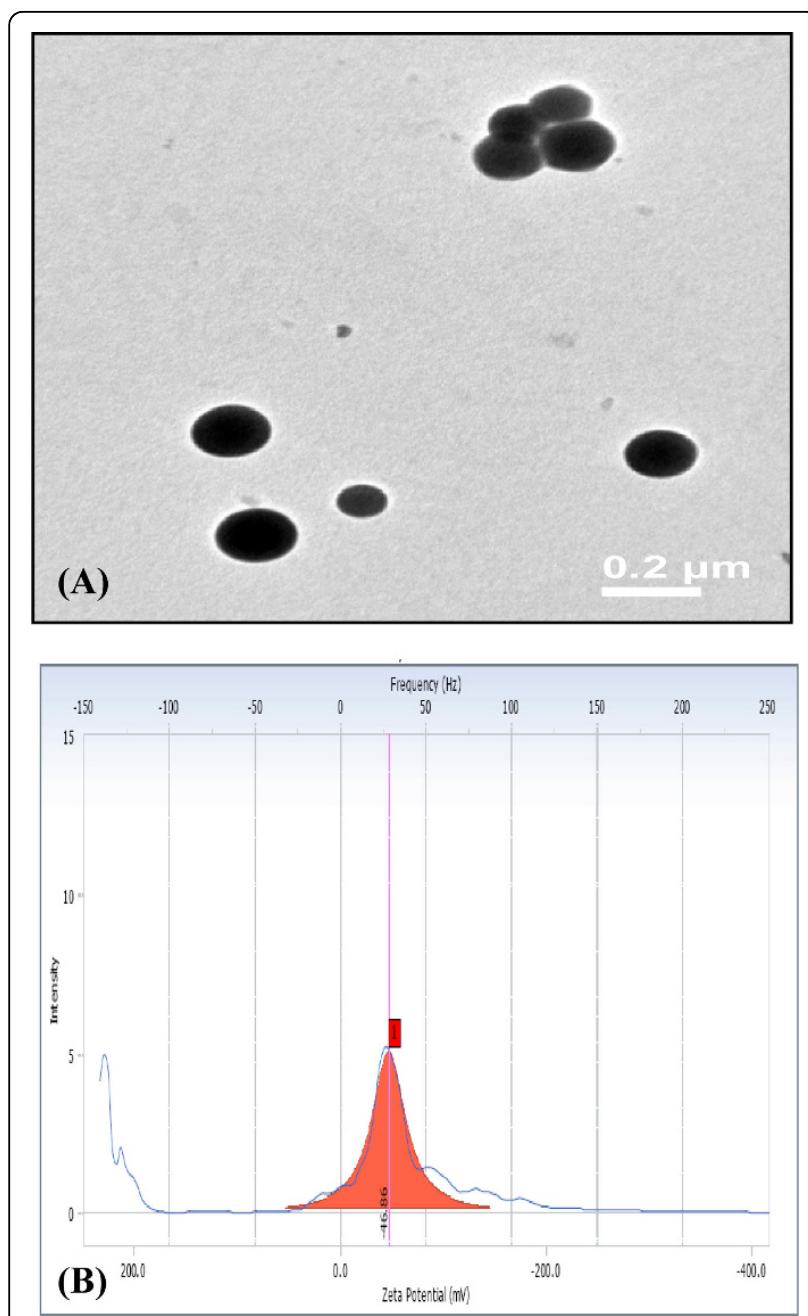

Figure 9 (A) Transmission electron micrograph of Se nanospheres isolated from the culture broth. (B) Zeta potential measurement of the selenium nanoparticles. bacterial species $[27,28]$. Other organometallic forms of selenium like dimethylselenide and dimethyldiselenide are produced by Rhodospirillum rubrum and Rhodocyclus tenuis while growing phototrophically in the presence of selenate [29]. Pseudomonas fluorescens K27- a gram negative denitrifying facultative anaerobe isolated from the Kesterson Reservior, California has been reported to detoxify metalloids: $\mathrm{Se}, \mathrm{Te}, \mathrm{Sb}$ which are reduced to the elemental form and further to some extent to -2 oxidation state along with biomethylation. The presence of volatile compounds of Se: dimethyl selenide (DMSe, $\mathrm{CH}_{3} \mathrm{SeCH}_{3}$ ), dimethyl diselenide (DMDSe, $\mathrm{CH}_{3} \mathrm{SeSeCH}_{3}$ ), dimethyl selenenyl sulfide $\left(\mathrm{DMSeS}, \mathrm{CH}_{3} \mathrm{SeSCH}_{3}\right.$ ) have been reported in the headspace of the cultures amended with soluble selenium salts [30].

Majority of metal transformations in anaerobic and aerobic environments are the result of the direct enzymatic activity of bacteria [31]. The bacterial reduction of selenate $\left(\mathrm{SeO}_{4}{ }^{2-}\right)$ to selenite $\left(\mathrm{SeO}_{3}{ }^{2-}\right)$ is known to occur through dissimilatory pathways [12,24,32], the reduction of selenite $\left(\mathrm{SeO}_{3}{ }^{2-}\right)$ to $\mathrm{Se}^{0}$, which is a common feature of many diverse microorganisms, is also not well understood. In the present study selenite reduction activity was observed mainly in the membrane fraction when it was incubated in the presence of selenite as a substrate [Fig. 10B]. However, there was nominal activity in the soluble fraction after prolonged period $(12 \mathrm{~h})$ of incubation at $37^{\circ} \mathrm{C}$ [Fig. $10 \mathrm{C}$ ]. This may be attributed to some non-specific reduction of selenite or by the diffusible nature of the membrane associated reductase protein (s) which resulted in selenite reducing activity in the soluble fraction. Previously, it has been reported that $\mathrm{SeO}_{3}{ }^{2-}$ reduction may be catalysed by a periplasmic nitrite reductase [13,33], hydrogenase I [34] or through non-enzymatic reactions [26]. Lortie et al. [11] reported that the aerobic reduction of selenate $\left(\mathrm{SeO}_{4}{ }^{2-}\right)$ and selenite $\left(\mathrm{SeO}_{3}{ }^{2-}\right)$ to $\mathrm{Se}^{0}$ by a Pseudomonas stutzeri isolate functioned as a detoxification mechanism as there was no evidence of dissimilatory Se reduction by this microbe. Recent studies have indicated that NADPH/ NADH dependent selenate reductase enzymes bring about the reduction of selenium (selenite/selenate) oxyions $[35,36]$. In the medium where tellurite or selenate was absent no growth was observed but growth occurred in the presence of tellurite or selenate indicating that these reductases are probably respiratory enzymes. The reduction seems to be initiated by electron transfer from the NADPH/NADH by NADPH/ $\mathrm{NADH}$-dependent reductase as electron carrier. In some bacterial species selenite reduction may serve functions of detoxification and maintenance of redox component of the electron transport system by cytoplasmic reductase enzymes $[10,37,38]$. Evidence of selenite/selenate

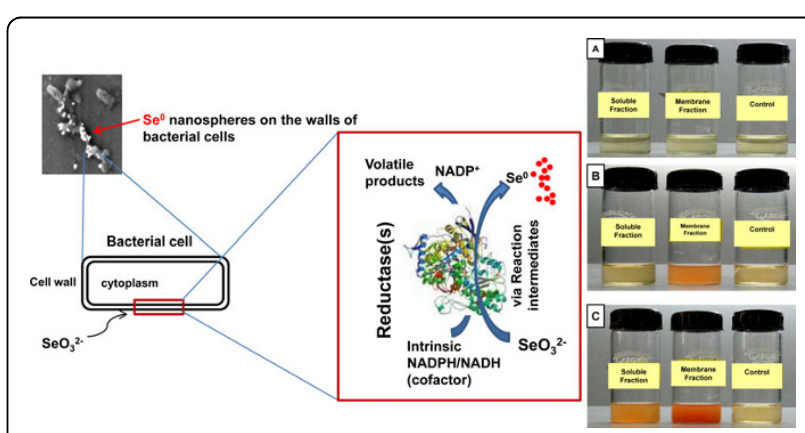

Figure 10 Schematic representation of proposed mechanism of biogenesis of Selenium ( $\mathrm{Se}^{0}$ ) nanospheres. (A) Selenite reduction at $0 \mathrm{~h}$. (B) Formation of red elemental selenium in membrane fraction after 3-4 h of incubation. (C) Prolonged incubation of $12 \mathrm{~h}$ resulted in formation of red elemental selenium in soluble fraction also. 
reduction via membrane-associated reductase(s) followed by rapid expulsion of selenium particles was reported by Losi and Frankenberger [10]. On the basis of experimental observations and the available literature the possible mechanism of formation of selenium nanospheres by the strain CM100B is proposed in Fig. 10. The toxic selenite anions are probably being reduced by membrane associated reductase(s). The transformation process is carried out via reaction intermediates which are still uncharacterized. The end product of the transformation process results in volatile methylated forms of selenium and formation of selenium nanostructures which are being expelled out in the culture broth by the bacterial cells. However, the exact mechanism of the reduction of selenite oxyions is yet to be deciphered completely. Clearly, additional work is needed to elucidate the enzymology involved in the reduction processes of selenium oxyions in aerobic conditions.

\section{Conclusions}

Several potential advantages revolve around the microbe's ability to grow in aerobic conditions which include rapid ability to generate more number of bacterial cells within a short time period and less stringent culture conditions. The aerobically produced nanoparticles by the microbe Bacillus cereus (strain CM100B) have been characterized in this study. Biosynthesis of amorphous $\mathrm{Se}^{0}$ nanospheres under aerobic conditions offers advantages over chemical processes, in which amorphous $\mathrm{Se}^{0}$ is produced under environmentally harmful conditions. The strain tolerates high levels of selenium oxyions and generates extracellular nanospheres of selenium ( 150-200 $\mathrm{nm}$ in diameter) which can be easily separated from the bacterial biomass by a simple centrifugation step without any post preparative treatment. The amorphous selenium nanospheres formed during the aerobic detoxtification of selenite by the strain CM100B were observed to be highly stable due to the presence of high negative charge. This green route of biosynthesis of selenium nanospheres is a simple, economically viable and an eco-friendly process resulting in nearly monodispersed highly stable selenium nanospheres. Further studies would determine if the diverse properties of the biologically based selenium nanospheres are comparable to chemically synthesized selenium nanoparticles and whether biologically synthesized selenium nanoparticles have practical applications in the field of nanotechnology and biotechnology.

\section{Acknowledgements}

We thank the Director, IMTECH Chandigarh for providing the facilities for this work. The authors duly acknowledge the financial support from Council for Scientific and Industrial Research (CSIR), Government of India.

\section{Authors' contributions}

SD planned and performed the experiments. SSC supervised the work. SD and SSC wrote the final version of the manuscript. The authors approved the final version of the manuscript.

\section{Competing interests}

The authors declare that they have no competing interests.

Received: 15 May 2010 Accepted: 5 July 2010 Published: 5 July 2010

\section{References}

1. Zhang J, Zhang SY, Xu JJ, Chen HY: A New Method for the Synthesis of Selenium Nanoparticles and the Application to Construction of $\mathrm{H}_{2} \mathrm{O}_{2}$ Biosensor. Chinese Chem Lett 2004, 15:1345-1348.

2. Zhang Y, Zhang J, Wang HY, Chen HY: Synthesis of selenium nanoparticles in the presence of polysaccharides. Mater Lett 2004, 58:2590-2594.

3. Yost DA, Russel JC, Yang H: Non-metal colloidal particle immunoassay. 1990, U.S. Patent 4954452.

4. Ip C: Selenium and ER stress response: Implication and exploitation for cancer therapy. Abstr Proc Int Conference on selenium in Biology and Medicine, Univ. Wisconsin, Madison 2006, 63.

5. Gao X, Zhang J, Zhang L: Hollow sphere selenium nanoparticles. Their in-vitro anti-hydroxyl radical effect. Adv Mater 2002, 14:290-293.

6. Wang $H$, Zhang J, Yu $H$ : Elemental selenium at nano size possesses lower toxicity without compromising the fundamental effect on selenoenzymes: Comparison with selenomethionine in mice. Free Radic Biol Med 2007, 42:1524-1533.

7. Peng D, Zhang J, Liu Q, Taylor EW: Size effect of elemental selenium nanoparticles (Nano-Se) at supranutritional levels on selenium accumulation and glutathione S-transferase activity. J Inorg Biochem 2007, 101:1457-63.

8. Shin Y, Blackwood JM, Bae I-T, Arey BW, Exarhos GJ: Synthesis and stabilization of selenium nanoparticles on cellulose nanocrystal. Mater Lett 2007, 61:4297-4300.

9. Thakkar KN, Mhatre SS, Parikh RY: Biological synthesis of metallic nanoparticles. Nanomedicine: NBM 2009, 6:257-262.

10. Narasingarao P, Haggblom MM: Identification of anaerobic selenaterespiring bacteria from aquatic sediments. Appl Environ Microbiol 2007, 73:3519-3527.

11. Lortie L, Gould WD, Rajan S, Meeready RGL, Cheng KJ: Reduction of elemental selenium by a Pseudomonas stutzeri isolate. Appl Environ Microbiol 1992, 58:4042-4044.

12. Oremland RS, Blum JS, Culbertson CW, Visscher PT, Miller LG, Dowdle P, Strohmaier FE: Isolation, Growth and Metabolism of an Obligately Anaerobic, Selenate-Respiring Bacterium, Strain SES-3. Appl Environ Microbiol 1994, 60:3011-3019.

13. Sabaty $M$, Avazeri $C$, Pignol $D$, Vermeglio A: Characterization of the reduction of selenate and tellurite by nitrate reductases. Appl Environ Microbiol 2001, 67:5122-5126.

14. Oremland RS, Herbel MJ, Blum JS, Langley S, Beveridge TJ, Ajayan PM, Sutto T, Ellis AV, Curran S: Structural and spectral features of selenium nanospheres produced by Se-respiring bacteria. Appl Environ Microbiol 2004, 70:52-60.

15. Tejo Prakash N, Sharma N, Prakash R, Raina KK, Fellowes J, Pearce Cl, Lloyd JR, Pattrick RAD: Aerobic microbial manufacture of nanoscale selenium: exploiting nature's bio-nanomineralization potential. Biotechnol Lett 2009, 31:1857-1862.

16. Yadav V, Sharma N, Prakash R, Raina KK, Bharadwaj LM, Tejo Prakash N: Generation of Selenium containing Nano-structures by soil bacterium, Pseudomonas aeruginosa. Biotechnol 2008, 7:299-304.

17. Tamura K, Dudley J, Nei M, Kumar S: Molecular Evolutionary Genetics Analysis (MEGA) software version 4.0. Mol Biol Evol 2007, 24:1596-1599.

18. Yudovich Ya E, Ketris MP: Selenium in coal: A review. Int J Coal Geol 2006, 67:112-126.

19. Dungan RS, Yates SR, Frankenberger WT: Transformations of selenate and selenite by Stenotrophomonas maltophilia isolated from a seleniferous agricultural drainage pond sediment. Environ Microbiol 2003, 5:287-295.

20. Pages D, Rose J, Conrod S, Cuine S, Carrier P, Heulin T, Achouak W: Heavy Metal Tolerance in Stenotrophomonas maltophilia. Plos One 2008, e1539, doi: 10.1371/journal. pone. 0001539. 
21. Kessi J, Ramuz M, Wehrli E, Spycher M, Bachofen R: Reduction of selenite and detoxifixation of elemental selenium by the phototrophic bacterium Rhodospirillum rubrum. Appl Environ Microbio/ 1999, 65:4734-4740.

22. Roux M, Sarret G, Paintrand IP, Fontecave M, Coves J: Mobilization of selenite by Ralstonia metallidurans CH34. Appl Environ Microbiol 2001 67:769-773.

23. Lin $\mathrm{ZH}$, Wang CRC: Evidence on the size-dependent absorption spectral evolution of selenium nanoparticles. Mater Chem Phy 2005, 92:591-594.

24. Losi M, Frankenberger WT Jr: Reduction of selenium by Enterobacter cloacae SLD1a-1: isolation and growth of bacteria and its expulsion of selenium particles. Appl Environ Microbiol 1997, 63:3079-3084.

25. Switzer-Blum J, Bindi AB, Buzzelli J, Stolz JF, Oremland RS: Bacillus arsenicoselenatis sp. nov. and Bacillus selenitireducens sp. nov.: two haloalkaliphiles from Mono Lake California that respire oxyions of selenium and arsenic. Arch Microbiol 1998, 171:19-30.

26. Tomei FA, Barton LL, Lemanski CL, Zocco TG: Reduction of selenate and selenite to elemental selenium by Wolinella succinogenes. Can $J$ Microbiol 1992, 38:1328-1333.

27. Chasteen TG: Confusion between dimethyl selenenyl sulfide and dimethyl selenone released by bacteria. Appl Organomet Chem 1993, 7:335-342

28. Swearingen JW Jr, Fuentes DE, Araya MA, Plishker MF, Saavedra CP, Chasteen TG, Va'squez CC: Expression of the ubiE Gene of Geobacillus stearothermophilus V in Escherichia coli K-12 Mediates the Evolution of Selenium Compounds into the Headspace of Selenite- and SelenateAmended Cultures. Appl Environ Microbiol 2006, 72:963-967.

29. Zehr JP, Oremland RS: Reduction of selenate to selenide by sulfate respiring bacteria: experiments with cell suspensions and estuarine sediments. Appl Environ Microbiol 1987, 53:1365-1369.

30. Ranjard L, Prigent-Combaret C, Nazaret S, Cournoyer B: Methylation of Inorganic and Organic Selenium by the Bacterial Thiopurine Methyltransferase. J Bacteriol 2002, 184:3146-3149.

31. Yurkov W, Beatty JT: Aerobic anoxygenic phototrophic bacteria. Microbiol Mol Biol Rev 1998, 62:695-724.

32. Macy JM: Biochemistry of selenium metabolism by Thauera selenatis gen. nov. sp. nov. and uses of the organism for bioremediation of selenium oxyanions in San Joaquin Valley drainage water. Selenium in the environment. Marcel Dekker, Inc., New York N.YFrankenberger WT Jr, Benson S 1994, 421-444.

33. DeMoll-Decker H, Macy JM: The periplasmic nitrite reductase of Thauera selenatis may catalyze the reduction of selenite to elemental selenium. Arch Microbiol 1993, 160:241-247.

34. Yanke LJ, Bryant RD, Laishley EJ: Hydrogenase (I) of Clostridrium pasteurianum functions a novel selenite reductase. Anaerobe 1995, 1:61-67.

35. Etezad SM, Khajeh K, Soudi M, Ghazvini PTM, Dabirmanesh B: Evidence on the presence of two distinct enzymes responsible for the reduction of selenate and tellurite in Bacillus sp. STG-83. Enzyme Microb Tech 2009, 45:1-6.

36. Hunter WJ, Manter DK: Reduction of selenite to elemental red selenium by Pseudomonas sp. strain CA5. Curr Microbiol 2009, 58:493-498.

37. Belzile N, Wu GJ, Chen YW, Appanna VD: Detoxification of selenite and mercury by reduction and mutual protection in the assimilation of both elements by Pseudomonas fluorescens. Sci Total Environ 2006, 367:704-714.

38. Yamada A, Miyashita M, Inoue K, Matsunaga T: Extracellular reduction of selenite by a novel marine photosynthetic bacterium. Appl Microbiol Biotechnol 1997, 48:367-372.

doi:10.1186/1475-2859-9-52

Cite this article as: Dhanjal and Cameotra: Aerobic biogenesis of selenium nanospheres by Bacillus cereus isolated from coalmine soil. Microbial Cell Factories 2010 9:52.

\section{Submit your next manuscript to BioMed Central and take full advantage of:}

- Convenient online submission

- Thorough peer review

- No space constraints or color figure charges

- Immediate publication on acceptance

- Inclusion in PubMed, CAS, Scopus and Google Scholar

- Research which is freely available for redistribution

Submit your manuscript at www.biomedcentral.com/submit 